\title{
Acceptance and use of big data techniques in services companies
}

\author{
Juan-Pedro Cabrera-Sánchez, Ángel F. Villarejo-Ramos* \\ University of Sevilla, Spain
}

\section{A R T I CLE INFO}

\section{Keywords}

Big data

Intention behaviour

UTAUT

Use resistance

Perceived risk

Opportunity cost

Services companies

\begin{abstract}
A B S T R A C T
Companies able to take advantage of the information coming from the use of Big Data will have a competitive advantage by being able to make decisions based on greater knowledge of customers and competition. Besides, the access to the software for the treatment of this great amount of data is free. So, the objective of this paper is to study the level of acceptance and use of these technologies, Big Data techniques, by services companies. To analyse the intention and use it extends the acceptance technologies model- Unified Theory of Acceptance and Use of Technology (UTAUT) - to the context of Big Data techniques, incorporating the effect on it of three new variables: resistance to use, perceived risk and opportunity cost. The structural model was evaluated using partial least squares structural equation modelling (PLS-SEM) with an adequate global fit. The verification is carried out with a sample of 199 Spanish services companies, and its main results are the strong effect of the facilitating conditions on the intention and use of Big Data, as well as the direct effect of the opportunity cost and the resistance to use on the intention, and the indirect inhibiting effect of the perceived risk through the resistance to use on intention behaviour.
\end{abstract}

\section{Introduction}

The exponential increase in the calculation capacity of computers together with the great development of new statistical techniques has made it possible to practically process huge amounts of data in real time. In this sense, all these techniques that are part of the revolution brought by Big Data, have meant a total change in the use of information within companies, both in the way in which data are managed and stored and in the way in which they are processed, analysed and interpreted (Agrawal et al., 2011). Big Data is a technology that allows storing, processing and combining huge amounts of different types of data obtained from different sources (Brünink, 2016), large datasets, unstructured and captured almost in real time.

Data management and storage techniques fall within the field of engineering. In the field of marketing study, data analysis is the most relevant activity. Sivarajah, Kamal, Irani, and Weerakkody (2016) proposed the classification of the different types of data analytics: 1) descriptive analytics, techniques that help know what has happened; 2) inquisitive analytics are those that help understand why something is happening; 3) predictive analytics are those that help anticipate what is most likely to happen in the future; 4) prescriptive analytics, techniques that answer the question "what now?" and 5) preventive analytics, techniques that help to recommend what needs to be done.

All these techniques are useful to us to apply them to the treatment of the great amount of information that come from heterogeneous data of: texts, audio, video, social media, data in general and Artificial Intelligence. These large blocks are not mutually exclusive as they can be used together, although each block has specific techniques and algorithms. Applying this great variety of Big Data Analytic techniques, it is possible, for example, to distinguish photographs, and recognise voices, discovering patterns of consumer behaviour or any other phenomenon for which there are data. Rehman, Chang, Batool \& Wah (2016) propose a summary of these data analysis techniques and methods for Big Data, which is shown in Table 1:

The good use of these techniques gives companies that use them an important competitive advantage over the rest of companies in their sector (Sivarajah et al., 2016), notably helping to make data-based decisions (McAfee and Brynjolfsson, 2012).

But the implantation, acceptance and use of a technology in the decision-making core of companies involves overcoming the brakes arising from ignorance of techniques, resistance to technological change, fear and anxiety, in addition to the limitations of the technology itself to implement (Yaqoob et al., 2016).

The literature review about Big Data Techniques, such as is shown in the previous table, indicates a greater concern for the purely technical aspects of the tools themselves and their applications (Sivarajah et al., 2016), not focusing on aspects related to the intention and use of them by companies. Only a few works have focused their study on companies' intentions of adopting Big Data Techniques (Brünink, 2016; Demoulin and Coussement, 2018; Huang et al., 2012;

\footnotetext{
* Corresponding author.

Email address: curro@us.es (Á.F. Villarejo-Ramos)
} 
Table 1

Data analysis techniques and methods for Big Data.

\begin{tabular}{lll}
\hline Type & Method & Description \\
\hline $\begin{array}{l}\text { Machine } \\
\text { learning }\end{array}$ & $\begin{array}{l}\text { Supervised } \\
\text { learning }\end{array}$ & $\begin{array}{l}\text { Supervised learning methods predict future events from } \\
\text { models which learn and are trained using data with } \\
\text { certain labels. These models are trained and tested with } \\
\text { crossed validation using various algorithms. The models } \\
\text { of supervised learning are much used to classify and to } \\
\text { group data (clustering). However, they have the } \\
\text { limitation of handling fast changes in Big Data. } \\
\text { Non-supervised learning models are trained with data } \\
\text { without labelling and serve to predict future events. } \\
\text { They are mainly used for grouping data (clustering). } \\
\text { Non- } \\
\text { supervised } \\
\text { learning } \\
\text { Semi- } \\
\text { supervised } \\
\text { learning }\end{array}$ \\
& $\begin{array}{l}\text { Semi-supervised learning models are initially developed } \\
\text { with labelled data and they are constantly updated with } \\
\text { the positive information produced by each correct } \\
\text { prediction of events. The adaptive behaviour of these } \\
\text { models do enable handling changes in the information. }\end{array}$ \\
\hline
\end{tabular}

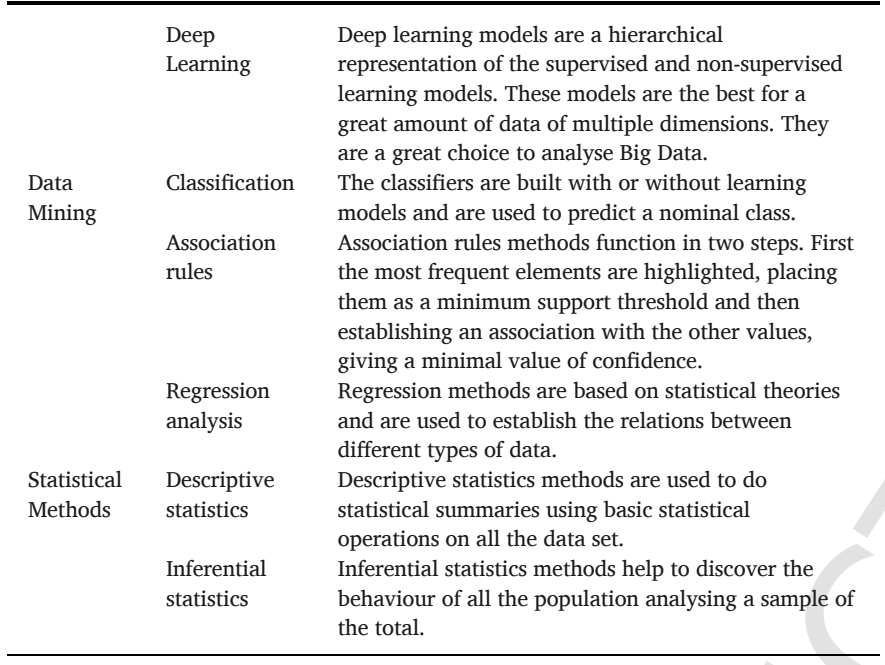

Table 2

Companies of the sample according to revenue and services activity.

\begin{tabular}{lllllll}
\hline Sector & $<2 \mathrm{M}$ & $\begin{array}{l}2 \mathrm{M} €- \\
10 \mathrm{M} €\end{array}$ & $\begin{array}{l}10 \mathrm{M} €- \\
43 \mathrm{M} €\end{array}$ & $\begin{array}{l}>43 \mathrm{M} \\
€\end{array}$ & $\begin{array}{l}\text { Not } \\
\text { answered }\end{array}$ & Total \\
\hline $\begin{array}{l}\text { Retail and } \\
\text { distribution }\end{array}$ & 6 & 7 & 3 & 11 & & 27 \\
$\begin{array}{l}\text { Communications } \\
\text { Education }\end{array}$ & 6 & 2 & 4 & 14 & 1 & 27 \\
$\begin{array}{l}\text { Financial } \\
\text { services }\end{array}$ & 4 & 1 & 1 & 6 & & 12 \\
$\begin{array}{l}\text { Health services } \\
\text { Other services }\end{array}$ & 8 & 3 & 2 & 12 & & 15 \\
Total & 59 & $\mathbf{3 5}$ & 22 & 8 & & 21 \\
\hline
\end{tabular}

Verma et al., 2018), but their studies have used the original TAM (Davis, 1985), TAM2 (Venkatesh and Davis, 2000) or TAM3 (Venkatesh and Bala, 2008), or the UTAUT model without any added variables.

This paper aims to identify, based on the acceptance model of technology UTAUT- Unified Theory of Acceptance and Use of Technology (Venkatesh et al., 2003), and with the inclusion of three new variables related to aspects, what may lead the services company not to use Big Data techniques: resistance to use, perceived risk and opportunity cost. Thus, it would be possible to understand the factors that affect the adoption and use of techniques derived from Big Data in services companies and analyse possible problems for their implementation.
The structure of the work begins with a bibliographic review of the variables and relationships of the proposed causal model. The third section describes the methodology used in the research. The fourth describes and analyses the results obtained after applying the PLS estimation model to the observed sample. Finally, the main conclusions and limitations of the model are presented.

\section{Model proposal and hypothesis approach}

There have been several previous models developed to understand the acceptance of technologies, with the Theory of Reasoned Action-TRA (Fishbein and Ajzen, 1975), the Technology Acceptance Model-TAM (Davis, 1985), and the Theory of Planned Behaviour -TPB (Ajzen, 1991). Standing out as the most accepted. Starting from them, and integrating other models previously developed (TAM2 - Venkatesh and Davis, 2000), the Unified Theory of Technology Adoption and Use of Technology, or UTAUT (Venkatesh et al., 2003), a model is born as an integrating answer to explain the acceptance of technologies by companies.

The proposed model is different from previous ones on Big Data Analytics as it includes real Use and it is extended with new variables that improve the model's results. Brünink (2016) used the UTAUT without extensions and without Use. That model only had Behavioural Intention but not Use, which is an important issue to test Technology Acceptance. Other models (Demoulin \& Coussement, 2018; Brown and Venkatesh, 2005) were only focused on the support by Top Management of Big Data Applications while the majority still use TAM, TAM2 or TAM3 (Brown and Venkatesh, 2005; Huang et al., 2012; Verma et al., 2018) with their limitations in explaining the Use to illustrate the factors that affect the adoption of Big Data Techniques.

The determining variables of the UTAUT model are: 1) Performance expectancy (PE), measured as the degree of benefit to the company from the use of a technology; 2) Effort expectancy (EE), measured by the degree of ease associated with the use of the technology; 3) Social influence (SI) from the perceptions of friends and family regarding the use of a technology; and 4) Facilitating conditions (FC), perceptions of technology users about the resources and support that are available to develop the use behaviour. The four variables directly influence the intention to use (behaviour intention, BI), and the facilitating conditions also influence the use of the new technology (usage behaviour, UB).

As Arenas-Gaitán, Peral-Peral and Villarejo-Ramos (2016) point out, the value of this model lies in its ability to identify the main determinants of adoption, and allows the inclusion and consideration of the effect of different moderators and variables that extend the model, thus increasing its explanatory power.

To the first-order constructs of the UTAUT model it adds the inhibitory effect on the intended use of resistance to use (RE) and perceived risk (PR) and the facilitating effect of opportunity cost (OC).

Now, the different hypotheses based on the extension of the UTAUT model in the case of the acceptance and use of Big Data by service companies are presented.

As stated in the original UTAUT proposal (Venkatesh et al., 2003), here is a positive relationship between expectations of outcome (performance expectancy, PE) and intention to use. This positive effect has been demonstrated in subsequent works (Brünink, 2016; Chauhan and Jaiswal, 2016; Yu, 2012), so it can be established as a Hypothesis:

Hypothesis 1Performance expectancy positively affects the user's intention to use Big Data in services companies.

Effort expectancy (EE) measures how easy the technology is to use, which will have a positive effect on the intended use. Subsequent studies reinforce the meaning and weight of this relationship (Al-Gahtani et al., 2007; Chauhan and Jaiswal, 2016; H. W. Kim, Chan and Gupta, 2007; Lee and Song, 2013; Yu, 2012) that confirm the ef- 
fect which the expected effort has on the intention to use. EE is the equivalent construct of Perceived Ease of Use used in the approach of Featherman and Pavlou (2003) and it has been checked in further studies (Chan and Lu, 2004). Other studies have confirmed the negative relationship between Effort Expectancy and Perceived Risk (Kim et al., 2008; Lee and Song, 2013).

However, the expectations of effort for technologies less easy to learn and use have sometimes provoked negative reactions on the part of users. Therefore, the easier Big Data is to use, the lower the perceived risk of the user to use it in their company (Martins et al., 2014). For all these reasons, the following two hypotheses are set out:

Hypothesis 2a: Effort expectancy positively affects the user's intention to use Big Data in services companies.

Hypothesis $2 \mathrm{~b}$ : Effort expectancy negatively affects the perceived risk of the use of the Big Data service.

In order to measure the effect of the influence perceived by the users of the technology with respect to what others (family and friends, mainly) think about the use of it, the initial proposal of UTAUT (Venkatesh et al., 2003) and the subsequent extension of UTAUT 2 (Venkatesh et al., 2012) use the social influence (social influence, SI). In the work and professional context, social influence is exerted by colleagues and superiors within the organisation, as reflected in various works on the subject (Al-Gahtani et al., 2007; Brünink, 2016; Chauhan and Jaiswal, 2016; Gupta et al., 2010; H. W. Kim et al., 2007; Lee and Song, 2013). This is how the Hypothesis is enunciated:

Hypothesis 3Social influence positively affects the behavioural intention in the use of a Big Data service.

The greater or lesser ease of access to the resources necessary for the acceptance and use of a technology, as well as the support once implemented, is what is measured with the construct facilitating conditions (FC), according to the proposal of Venkatesh et al. (2003) where a significant effect on the intention to use is demonstrated. Subsequent works corroborate this (Duyck et al., 2010;Hung et al., 2007 Wu et al., 2007). According to the Theory of Planned Behaviour (TPB) (Ajzen, 1991) and the endorsement of subsequent works (Al-Gahtani et al., 2007; Brünink, 2016; Chauhan and Jaiswal, 2016; Duyck et al., 2010; Kim et al., 2007), the positive effect of facilitating conditions also acts on use and not only on intention. Therefore, the following two hypotheses can be enunciated:

Hypothesis 4a: Facilitating conditions positively affect the behavioural intention in the use of a Big Data service.

Hypothesis 4b: Facilitating conditions positively affect the use of a Big Data service.

Perceived risk (PR) has been measured in relation to the risk perceived by the user when faced with a new technology and acts as a brake on its implementation. There is enough literature that includes PR as a negative antecedent in the intention of use (Kim et al., 2008; Lee and Song, 2013; Martins et al., 2014), besides the work of Featherman and Pavlou (2003). Pavlou and Gefen (2004) found that buyers' PR decreased their intention to buy. Later, this relationship was confirmed by Nicolaou and McKnight (2006).

Likewise, the trust in the use of a technology decreases its PR (Hsieh, 2015; Kim et al., 2008), while non-trust or resistance to its use increases it (Chen et al., 1998). On the other hand, the PR increases the predisposition to bad results, giving rise to a negative attitude that increases resistance to the use of this technology (Bhattacherjee and Hikmet, 2007; Fishbein and Ajzen, 1975). PR also increases the expectation of negative results, consequently raising the resistance to using the technology (Lapointe and Rivard, 2005).
As for users who perceive the use of a technology as safe, they will tend to perceive it as useful and expect a better result (Chan and Lu, 2004). At the same time, those who perceive less effort in the use of a technology will be those who do not perceive risk in its use (Martins et al., 2014; Featherman and Pavlou, 2003).

Hypothesis 5a: Perceived risk negatively influences the intention to use a Big Data service.

Hypothesis 5b: The perceived risk of use positively influences the resistance to the use of a Big Data service.

Hypothesis 5c: The perceived risk of use negatively influences the expectations of the result of the use of a Big Data service.

Another inhibiting factor is resistance to use (RU), which measures the user's opposition or negative reaction to a new technology. As Gibson (2004) points out, the implementation of many new technologies has been hampered by user opposition to their implementation. In this sense, resistance to use is defined as opposition to the change associated with implementing a new technology or information system (Kim and Kankanhalli, 2009; Lapointe and Rivard, 2005). Norzaidi, Salwani, Chong and Rafidah (2008) verified the relationship between user resistance and usage, also confirmed by Bhattacherjee and Hikmet (2007) and Poon et al. (2004), among other studies.

Despite these works, there are few studies, such as that of Hsieh (2015), which integrate the resistance to use in the UTAUT model as a negative precedent of the intention to use. It is stated as a Hypothesis:

Hypothesis 6Resistance to use negatively influences the intention to use a Big Data service.The opportunity cost (OC) has been understood as the potential loss in the search for a certain result in the implementation of a new technology. Although there is very little literature on the subject (Lu et al., 2005), it is worth noting that Zikmund and Scott (1974) have already stressed the importance of OC when making a purchase decision. Subsequently, Dowling and Staelin (1994) added that consumers need more information when making risky decisions, linking OC with PR. The following Hypothesis can therefore be formulated:

Hypothesis 7The opportunity cost positively influences the intention to use a Big Data service.

The direct relationship between BI and the use of technologies has been studied from Davis's generally accepted proposal (1985) of the Technology Acceptance Model (TAM) through to the proposal of the UTAUT model (Venkatesh et al., 2003) that predicted moderate effects on the background of the intention to use technologies, and via Fishbein \& Ajzen's Theory of Reasoned Action (TRA). There have been several streams of research in Technology Acceptance. One stream has focused on using intention or usage as a dependent variable while others have focused on implementation success at the organisational level or task-technology fit among others. In the UTAUT model, the goal is to understand usage as the dependent variable (Venkatesh et al., 2003) while the role of intention is to predict a behaviour as set by Ajzen (1991).

The direct influence between UB and BI has been contrasted in subsequent research in contexts as different as the adoption of internet banking in Portugal (Martins et al., 2014), the purchase of airline tickets in Spain (Escobar-Rodríguez and Carvajal-Trujillo, 2014), the use of Electronic Document Management System (EDMS) (Afonso et al., 2012) and the adoption of ERPs in India (Chauhan and Jaiswal, 2016). Therefore, the last Hypothesis has been enunciated as:

Hypothesis 8The user's behavioural intention favourably influences the use of a Big Data service. 
As a consequence of the hypotheses previously justified, an acceptance and use model of Big Data services for companies can be proposed, as shown in the following Fig. 1.

\section{Research methodology}

In order to contrast the structural model, a sample of managers responsible for areas such as Human Resources, Finance, Marketing and Sales, or the CEO of Spanish service companies of different sizes in relation to the sales was used, as shown in Table 1.

The data were collected during the months of September and October 2018 by means of a self-managed online survey, sent through personalised emails to a database compiled by the researchers themselves using their network of contacts. In order to eliminate possible ambiguities in the questionnaire, it was previously reviewed, as a pre-test, with 5 volunteer managers and 5 researchers. The number of valid surveys finally received was 199, managers of each company, with a response rate of $35 \%$ out of the total of questionnaires sent (see Table 2 .

The measurement scales for the model's different variables, mostly from the original UTAUT proposal (Venkatesh et al., 2003), have been adapted to Big Data. The scales used can be consulted in Appendix 1 . The statement of the different items in each case as well as the sources from which each scale has been adapted from original references. All items are measured with 1-7 Likert scales.

The model has been statistically treated using PLS-SEM estimation to analyse the reliability and validity of the measurement scales and to evaluate the structural model (Chin and Dibbern, 2010; Hair et al., 2012). Specifically, the SmartPLS 3 software (Ringle et al., 2015) has been used. PLS-SEM was chosen to estimate the model because our model has composites or a mix of composites with common factor variables (Rigdon et al., 2017; Sarstedt et al., 2016). Another major purpose was to predict key constructs such as Behavioural Intention or Use (Shmueli et al., 2016) besides identifying key constructs (Hair et al., 2017). The model is also complex with a great number of indicators and constructs, so PLS-SEM fits the requirements for evaluating the model (Chin and Dibbern, 2010; Hair et al., 2016).

To check the absence of measurement bias error in the sample or Common Method Bias (CMB), the recommendations of Kock (2015), Kock and Lynn (2012) and Podsakoff et al. (2003) have been followed, incorporating into the questionnaire a new latent variable called the CMB variable as dependent on the previous ones of the model, measured with an indicator not previously used. All variance inflation factors (VIF) obtained by this method must be less than 3.3 to confirm that the sample had no measurement bias error (Table 3 ).

\section{Results}

To estimate the measurement model the individual reliability and validity of the model was checked following recommendations from works using the PLS-SEM estimation (Henseler et al., 2014; Roldán and Sánchez-Franco, 2012). The required values for individual factorial loads must reach at least 0.7 of their own latent variables for constructs measured in mode B. This level is reached by all the indicators, except FC3 and OC2, which have been eliminated from their respective measurement scales, recalculating them for the new situation, obtaining loads above the minimum in all cases. This shows the adequate individual reliability of the model's measurement scales.

In order to analyse the reliability of the constructs the values of Cronbach's alpha is checked, requiring a minimum value of 0.7 as suggested by Nunnally (1978) and the composite reliability, which must be above 0.9 in all cases. Convergent validity is tested by analysing the mean extracted variance (AVE), with values for all variables above the proposed 0.5 (Straub et al., 2004). All the indicators of the measurement scales of the model have surpassed these requirement levels. Therefore, the composite reliability and convergent validity of these scales can be affirmed.

In order to check the discriminant validity, a double test is used which increases the levels of demand placed on the model. Firstly, by means of the Fornell and Larcker test (Barclay et al., 1995) which compares the square root of the AVE of each latent variable with the correlations of this variable with the rest shown in the diagonal of Table 4. Secondly, the more restrictive method of the Heterotrait-Monotrait ratio (HTMT) (Henseler et al., 2014) was used, verifying (Table 5) that in all cases these correlations reach levels lower than 0.9. Therefore, affirm the discriminant validity of all the latent variables used can be affirmed.

For the estimation of the complete structural model, the values of the coefficients paths between variables are analysed to determine the intensity of the relationship and the explained variance (measured by $\mathrm{R}^{2}$ ) of the endogenous variables, intention of use and use of the Big Data services. For this purpose, bootstrapping with 15,000 sub-samples is used to calculate the reliability of the paths coefficients in the relationships presented in the structural model. The values obtained for the

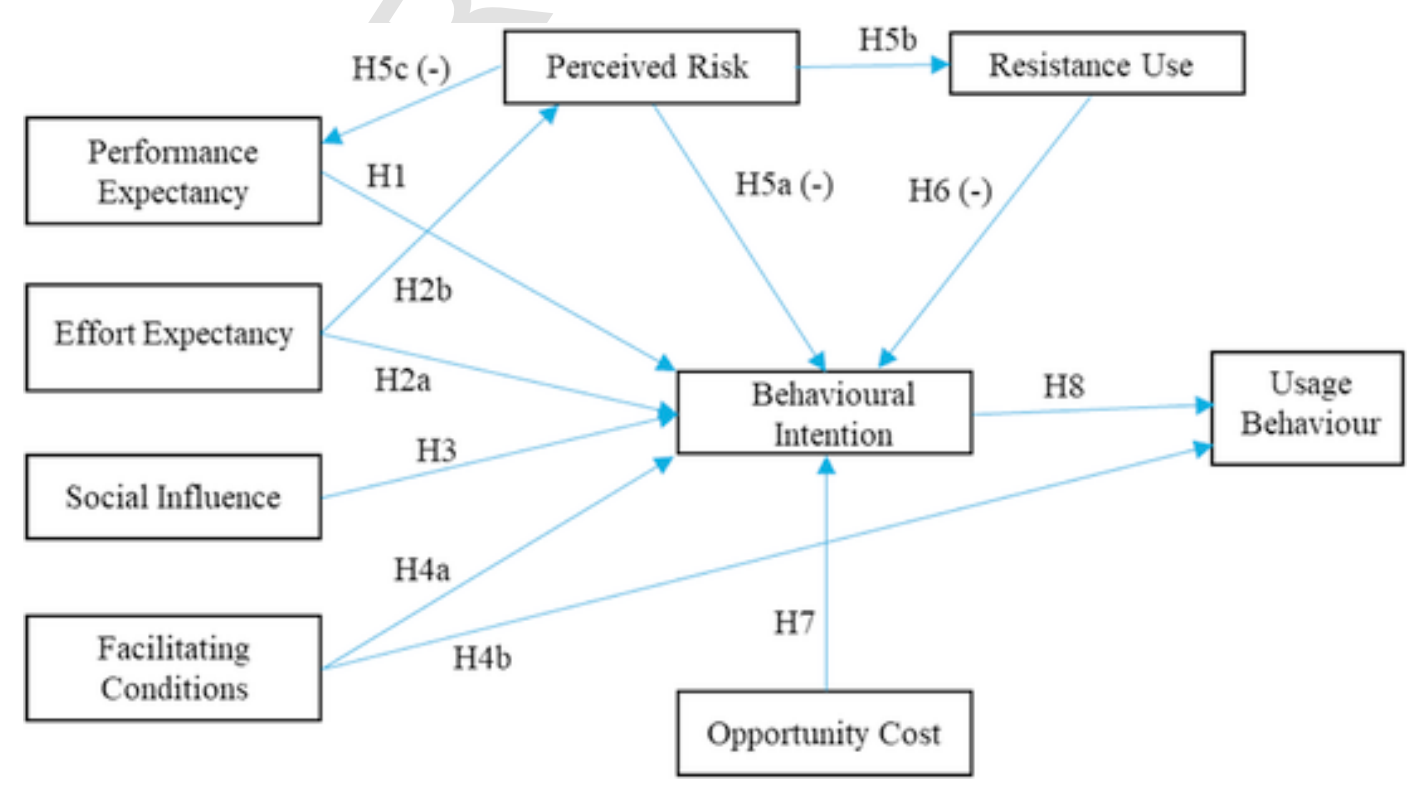

Fig. 1. Model of acceptance of Big Data in services companies. 
Table 3

VIF from all variables to check CMB.

\begin{tabular}{ll}
\hline & CMB \\
\hline Behavioural Intention & 1.835 \\
Effort Expectancy & 1.158 \\
Facilitating Conditions & 1.054 \\
Opportunity Cost & 1.178 \\
Perceived Risk & 1.255 \\
Performance Expectancy & 1.866 \\
Resistance to Use & 1.707 \\
Social Influence & 1.515 \\
\hline
\end{tabular}

loads between variables and the $\mathrm{R}^{2}$ of the endogenous variables of the model can be seen in Fig. 2 .

In addition, the SRMR indicator was calculated for the entire sample. SRMR is a measure of the overall fit of the model, especially suitable for PLS. In our case, a value of 0.064 was obtained, which ensures the fit of the model by offering levels lower than 0.08 proposed (Henseler et al., 2014), although with differences between the saturated model and the estimated model, so only the explanatory capacity of the model can be spoken of, not its confirmatory capacity.

The contrast between the model and the sample used highlights the acceptance of all the hypotheses with demanding levels of significance in all cases, except H2a, which is significant but in the opposite direction to that proposed, and H5a, which is not significant. See Table 6 .

The contrast of the model presents us with a high effect of the facilitating conditions, both on intention and on use. For its part, the perceived risk has an important effect on resistance to use and this in turn acts as a brake on the intention to use. The negative influence of the surviving risk on the expectations of results is also significant. The opportunity cost significantly affects the intention to use. And the relationship of intention to use is verified with a high weight and level of significance. Effort expectancy has only shown its significant influence as a reduction in perceived risk. Perform expectancy, on the other hand, does influence the intention to use, as does social influence. Although the correlation between EE and BI may be positive and the results show a negative relationship, the effect of Effort Expectancy on Behavioural Intention is not significant. Falk and Miller (1992) explained this effect (when the path coefficient and the correlation between the latent constructs do not have the same sign) known as the suppressor effect that means that two or more variables contain the same information and are, therefore, redundant. We have discovered a suppressor effect with Facilitating Conditions (FC) on Behaviour Intention (BI). Following the steps suggested by Falk \& Miller to solve this issue, we found that eliminating FC $\rightarrow$ BI the model lost predictive capacity and, even if the relationship $\mathrm{EE} \rightarrow \mathrm{BI}$ was positive, not significant.

The model finally shows a high explanatory power of $48.3 \%$ (see Fig. 2) above the minimum level recommended by Falk and Miller (1992) which is $10 \%$. The Stone-Geisser $Q^{2}$ has also been calculated to evaluate the model's predictive capacity (Gefen et al., 2011) and it is concluded that the model has predictive relevance as all the $\mathrm{Q}^{2}$ values of the table are greater than 0 (Roldán and Sánchez-Franco, 2012). The $\mathrm{Q}^{2}$ values confirm the model's predictive relevance. Specifically, the $\mathrm{Q}^{2}$ values are small (i.e., lower than 0.15); medium (i.e., 0.15-0.35) and high if higher than 0.35 (Fornell and Cha, 1994) as shown in Table 7.

\section{Conclusions, limitations and future research}

\subsection{Theoretical conclusions}

Our work extends the UTAUT model by incorporating three new variables: resistance to use, perceived risk and opportunity cost. Using this the aim is to increase the explanatory and predictive power of the model by adding variables that are understood to be decisive in the acceptance and use of Big Data services by companies. Using a sample of multi-sectorial companies with different invoicing allows us to establish a certain generalisation of the results obtained from the extended UTAUT model with respect to the acceptance and use of Big Data. In the line that was introduced at the beginning of the work, the use of

Table 4

Discriminant Validity (Fornell-Larcker's test).

\begin{tabular}{|c|c|c|c|c|c|c|c|c|c|}
\hline & BI & $\mathrm{EE}$ & FC & OC & PR & $\mathrm{PE}$ & RU & SI & UB \\
\hline Behavioural Intention & 0.979 & & & & & & & & \\
\hline Effort Expectancy & 0.380 & 0.851 & 7 & & & & & & \\
\hline Facilitating Conditions & 0.628 & 0.584 & 0.871 & & & & & & \\
\hline Opportunity Cost & 0.353 & 0.188 & 0.179 & 0.940 & & & & & \\
\hline Perceived Risk & -0.330 & -0.189 & -0.284 & -0.099 & 0.910 & & & & \\
\hline Performance Expectancy & 0.544 & 0.433 & 0.372 & 0.322 & -0.195 & 0.858 & & & \\
\hline Resistance to Use & -0.506 & -0.257 & -0.343 & -0.236 & 0.409 & -0.565 & 0.934 & & \\
\hline Social Influence & 0.497 & 0.458 & 0.483 & 0.180 & -0.244 & 0.478 & -0.234 & 0.792 & \\
\hline Usage Behaviour & 0.630 & 0.359 & 0.624 & 0.151 & -0.274 & 0.401 & -0.399 & 0.449 & 1.000 \\
\hline
\end{tabular}

Table 5

Discriminant validity (ratio Heterotrait-Monotrait -HTMT).

\begin{tabular}{|c|c|c|c|c|c|c|c|c|c|}
\hline & BI & $\mathrm{EE}$ & FC & OC & PR & $\mathrm{PE}$ & RU & SI & UB \\
\hline \multicolumn{10}{|l|}{ Behavioural Intention } \\
\hline Effort Expectancy & 0.380 & & & & & & & & \\
\hline Facilitating Conditions & 0.690 & 0.649 & & & & & & & \\
\hline Opportunity Cost & 0.374 & 0.197 & 0.205 & & & & & & \\
\hline Perceived Risk & 0.349 & 0.202 & 0.324 & 0.101 & & & & & \\
\hline Performance Expectancy & 0.559 & 0.449 & 0.411 & 0.344 & 0.206 & & & & \\
\hline Resistance to Use & 0.521 & 0.269 & 0.383 & 0.251 & 0.443 & 0.597 & & & \\
\hline Social Influence & 0.532 & 0.507 & 0.567 & 0.191 & 0.297 & 0.524 & 0.254 & & \\
\hline Usage Behaviour & 0.635 & 0.355 & 0.679 & 0.153 & 0.287 & 0.405 & 0.408 & 0.476 & \\
\hline
\end{tabular}




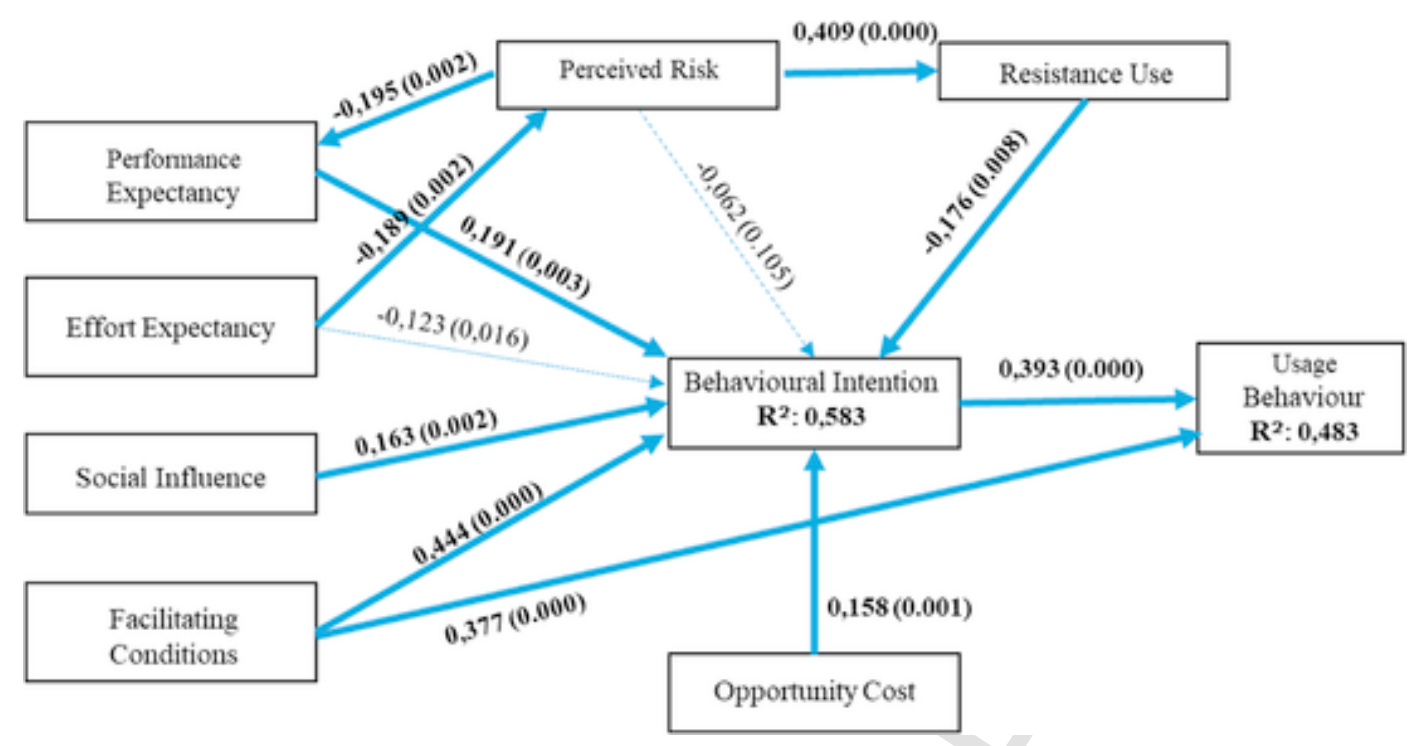

Fig. 2. Results of the model.

Table 6

Structural model estimates.

\begin{tabular}{|c|c|c|c|}
\hline Hypothesis & $\begin{array}{l}\text { Path } \\
\text { coefficients }\end{array}$ & $\begin{array}{l}\mathrm{P} \\
\text { Values }\end{array}$ & $\begin{array}{l}\text { Accepted } \\
\text { Hypotheses }\end{array}$ \\
\hline $\begin{array}{l}\text { H1: Performance } \\
\text { Expectancy } \rightarrow \text { Intention to use }\end{array}$ & $0.191 * *$ & 0.003 & YES \\
\hline $\begin{array}{l}\text { H2a: Effort Expectancy } \rightarrow \text { Intention } \\
\text { to use }\end{array}$ & -0.123 & 0.016 & NOT \\
\hline $\begin{array}{l}\text { H2b: Effort Expectancy } \rightarrow \text { Perceived } \\
\text { Risk }\end{array}$ & $-0.189 * *$ & 0.002 & YES \\
\hline $\begin{array}{l}\text { H3: Social Influence } \rightarrow \text { Intention to } \\
\text { use }\end{array}$ & $0.163 * *$ & 0.002 & YES \\
\hline $\begin{array}{l}\text { H4a: Facilitating } \\
\text { Conditions } \rightarrow \text { Intention to use }\end{array}$ & $0.444 * * *$ & 0.000 & YES \\
\hline $\begin{array}{l}\text { H4b: Facilitating Conditions } \rightarrow \text { Use } \\
\text { Behaviour }\end{array}$ & $0.377 * * *$ & 0.000 & YES \\
\hline $\begin{array}{l}\text { H5a: Perceived Risk } \rightarrow \text { Intention to } \\
\text { use }\end{array}$ & -0.062 & 0.105 & NOT \\
\hline $\begin{array}{l}\text { H6: Resistance to use } \rightarrow \text { Intention to } \\
\text { use }\end{array}$ & $-0.176 * *$ & 0.008 & YES \\
\hline $\begin{array}{l}\text { H5b: Perceived Risk } \rightarrow \text { Resistance to } \\
\text { use }\end{array}$ & $0.409 * * *$ & 0.000 & YES \\
\hline $\begin{array}{l}\text { H5c: Perceived Risk } \rightarrow \text { Performance } \\
\text { Expectancy }\end{array}$ & $-0.195 * *$ & 0.002 & YES \\
\hline $\begin{array}{l}\text { H7: Opportunity Cost } \rightarrow \text { Intention to } \\
\text { use }\end{array}$ & $0.158 * *$ & 0.001 & YES \\
\hline $\begin{array}{l}\text { H8: Intention to use } \rightarrow \text { Usage } \\
\text { Behaviour }\end{array}$ & $0.393 * * *$ & 0.000 & YES \\
\hline
\end{tabular}

***p $<0.001 ; * * \mathrm{p}<0.01 ; * \mathrm{p}<0.05$ ((bootstrapping with 15,000 sub-samples and 1-tailed test).

Significant relationships with path coefficients and $\mathrm{p}$ value in bold.

Table 7

Prediction of latent variables.

\begin{tabular}{lll}
\hline & RMSE & $\mathrm{Q}^{2}$ \\
\hline Behavioural Intention & 0.432 & 0.420 \\
Usage Behaviour & 0.502 & 0.320 \\
\hline
\end{tabular}

Big Data by the companies means the possibility of knowing better the market and the clients to whom they direct their offer based on this information and, therefore, to achieve a competitive advantage (Sivarajah et al., 2016). In this sense, using Big Data, the large amount of valuable information that the client provides us with and that helps us in making decisions (McAfee and Brynjolfsson, 2012) and in the design of strategies to improve customer relationship management is collected.

This model's results confirm the UTAUT (it comes from and unifies eight previous models) as the best model in Technology Acceptance as it explains more variance than previous models, such as the most tested and known TAM. Although TAM evolved towards TAM2 and TAM3, it still has some limitations, such as its use in complex situations with many users, integration with other models, real use prediction and the adoption by SMEs that are improved with the UTAUT model with the new variables proposed.

Focused on the results obtained in our research, it can be verified that the intention of use of Big Data by the companies is determined: 1) by the perception of obtaining good results with the implementation of this technology (PE); 2) by the positive effect that they mean in this technology that others consider important to use (SI); and 3) mainly by the fact that the company facilitates the support and the resources to promote its use (FC). This last relationship was not contemplated in the original UTAUT (Venkatesh et al., 2003) and was contemplated in UTAUT 2 (Venkatesh et al., 2012). On the other hand, it is seen that the intention of use is negatively affected by the resistance to the use of new technologies that exists in any organisation, although its influence is lower than the previous relations, as Hsieh (2015) presented. It can also be seen that, although the use of Big Data is perceived as difficult (EE), this influence is very low and not very significant on the intention of use. Curiously, the scale is formulated in a positive way and the greater the ease of use, the greater the intention to use, but a negative relationship is obtained (although not very significant). This could be explained by the fact that Big Data is perceived as a technology that is assumed to be difficult to implement and that, if it were easy to implement, little value would be obtained from it. It has also been possible to verify a strong positive influence of the facilitating conditions on the use of the new technology, contributing even more load than the Intention of Use to the thread of the conclusions obtained by Escobar-Rodríguez and Carvajal-Trujillo (2014).

Therefore, and after verifying the model, it is observed that all the hypotheses raised in the proposed extension of the UTAUT model except the H2a and the H5a, have been accepted. This can be transferred to the design of a model that improves the original model in line with the work of Featherman and Pavlou (2003). 


\subsection{Managerial implications}

As for the professional implications, it is assumed that although each new technology has its own learning curve, this has little influence when it comes to adopting it as long as great results are expected from it, as is the case with Big Data. Also, it seems that if services companies have the right infrastructure, nothing is lost by trying this new technology and that the inhibiting factors of this test have less weight than the benefits that companies expect. In this sense, it would be very important for companies to know that most of the software associated with the use of Big Data is free and if the company already has the necessary resources of hardware and qualified personnel it is much easier to adopt (Erevelles et al., 2016). Therefore, in companies with a certain level of technological implementation, at the level of hardware and personnel, it is very likely that they can implement and take advantage of the use of Big Data to identify the benefit of its use at the level of decision making in management and marketing. In short, for companies that are already using their data in some way, it will be easier to adopt this new technology and get a higher performance (Kwon et al., 2014).

Focused on the results of the research, service companies should be involved in the implementation and use of Big Data techniques, providing employees with the conditions to know and use these techniques to obtain information and use it in making decisions. In the same way, companies should back the training of their personnel in these techniques to avoid the resistance to their use that may come from the suspicion that employees have of a new technology to use in their daily work habits. The fear or risk of using an unknown technology must also be faced by the managers of the companies who must transfer to their employees the confidence and benefit of using Big Data techniques. Companies should take advantage of the fact that employees perceive an opportunity to use Big Data techniques in order to be more efficient in their work and increase the competitiveness of services companies.

\subsection{Limitations and future research}

The main limitation of this paper is that due to the maturity of the base model used (UTAUT), it is estimated that, in the case of acceptance and use of Big Data techniques in services companies, there are constructs of the original model, such as effort expectancy, which have a lower weight in their influence on the intention of use. So, three new preceding variables are included in our model proposal: resistance to use, perceived risk and opportunity cost, which leads us to think that there may be other variables that add value to UTAUT, such as technology fear or trust and, therefore, it is considered necessary in future research to include these variables, thus extending our conceptual model for Big Data.

Secondly, it seems necessary to explore in future research new moderating variables different from those of the original UTAUT in order to evaluate possible new effects not contemplated previously. Likewise, it would be necessary to look for more relationships in the proposed model that explain the differences between the saturated model and the estimated model.

Finally, the sample of services companies is small in order to make a good multi-group analysis and be able to evaluate possible differences in the intention and use of Big Data according to sectors of activity or size of the companies, among other classification variables. In this way, obtaining a larger sample of services companies which use Big Data technology will be our future challenge that will surely allow us to improve the results of this research.

\section{Appendix A. Supplementary data}

Supplementary data to this article can be found online at https://doi. org/10.1016/j.jretconser.2019.101888.

\section{References}

Afonso, C.M., González, M.O., Roldán-Salgueiro, J.L., Sánchez-Franco, M.J., 2012. Determinants of user acceptance of a local eGovernment electronic document management system (EDMS). In: 12th European Conference on e-Government: ECEG (19-28), Academic Publishing International Limited, Barcelona.

Agrawal, D., Bernstein, P., Bertino, E., 2011. Challenges and opportunities with big data 2011-1. In: Proceedings of the VLDB Endowment, vols. 1-16. Available from: http://dl. acm.org/citation.cfm?id = 2367572\%5Cnhttp://docs.lib.purdue.edu/cctech/1/.

Ajzen, I., 1991. The theory of planned behavior. Organ. Behav. Hum. Decis. Process. 50, 179-211. Available from: https://doi.org/10.1016/0749-5978(91)90020-T.

Al-Gahtani, S.S., Hubona, G.S., Wang, J., 2007. Information technology (IT) in Saudi Arabia: culture and the acceptance and use of IT. Inf. Manag. 44 (8), 681-691. Available from: https://doi.org/10.1016/j.im.2007.09.002.

Arenas-Gaitán, J., Peral-Peral, B., Villarejo-Ramos, A.-F., 2016. Grupos de mayores en la banca electrónica. Segmentación de clases latentes con PLS-POS. In: Congreso Marketing AEMARK (Madrid)

Barclay, D., Thompson, R., Higgins, C., 1995. The partial least squares (PLS) approach to causal modeling: personal computer adoption and uses as an ilustration. Technol. Stud.. Bhattacherjee, A., Hikmet, N., 2007. Physicians' resistance toward healthcare information technology: a theoretical model and empirical test. Eur. J. Inf. Syst. 16 (6), 725-737. Available from: https://doi.org/10.1057/palgrave.ejis.3000717.

Brown, S.A., Venkatesh, V., 2005. Model of adoption of technology in households: a baseline model test and extension incorporating household life cycle. MIS Q. 29 (3), 399-426. Available from: https://doi.org/10.2307/25148690.

Brünink, L., 2016. Cross-Functional Big Data Integration: Applying the Utaut Model, University of Twente, The Nederlands.

Chan, S., Lu, M., 2004. Understanding internet banking adoption and use behavior: a Hong Kong perspective. J. Glob. Inf. Manag. 12 (3), 21-43. Available from: https://doi. org/10.4018/jgim.2004070102.

Chauhan, S., Jaiswal, M., 2016. Determinants of acceptance of ERP software training in business schools: empirical investigation using UTAUT model. Int. J. Manag. Educ. 14 (3), 248-262. Available from: https://doi.org/10.1016/j.ijme.2016.05.005.

Chen, C.C., Chen, X., Meindl, J.R., 1998. How can cooperation be fostered?. Cult. Eff. Individualism-Collectivism 23 (2), 285-304.

Chin, W.W., Dibbern, J., 2010. Handbook of Partial Least Squares, pp. 171-193.

Available from: https://doi.org/10.1007/978-3-540-32827-8.

Davis, F., 1985. A Technology Acceptance Model for Empirically Testing New End-User Information Systems, Massachusetts Institute of Technology, p. 291 December 1985. Demoulin, N.T., Coussement, K., 2018. Acceptance of Text-Mining Systems: the Signaling Role of Information Quality, Information \& Management. Available from: https://doi. org/10.1016/j.im.2018.10.006.

Dowling, G.R., Staelin, R., 1994. A model of perceived risk and intended risk-handling activity. J. Consum. Res. 21 (1), 119-134. Available from: https://doi.org/10.1086/ 209386.

Duyck, P., Pynoo, B., Devolder, P., Voet, T., Adang, L., Ovaere, D., Vercruysse, J, 2010. Monitoring the PACS implementation process in a large university hospital-discrepancies between radiologists and physicians.. Journal of Digital Imaging 23 (1), 73-80. doi:https://doi.org/10.1007/s10278-008-9163-7.

Erevelles, S., Fukawa, N., Swayne, L., 2016. Big Data consumer analytics and the transformation of marketing. J. Bus. Res. 69 (2), 897-904. Available from: https://doi.org/10. 1016/j.jbusres.2015.07.001.

Escobar-Rodríguez, T., Carvajal-Trujillo, E., 2014. Online purchasing tickets for low cost carriers: an application of the unified theory of acceptance and use of technology (UTAUT) model. Tour. Manag. 43, 70-88. Available from: https://doi.org/10.1016/j. tourman.2014.01.017.

Falk, R.F., Miller, N.B., 1992. A Primer for Soft Modeling, University of Akron Press, Akron, Ohio (USA).

Featherman, M.S., Pavlou, P.A., 2003. Predicting e-services adoption: a perceived risk facets perspective. Int. J. Hum. Comput. Stud. 59 (4), 451-474. Available from: https:// doi.org/10.1016/S1071-5819(03)00111-3.

Fishbein, M., Ajzen, I., 1975. Belief attitude, intention and behavior. An introduction to theory and research. Philos. Rhetor. 10 (2), 130-132.

Fornell, C., Cha, J., 1994. Partial least squares,. In: Bagozzi, R. (Ed.), Advanced Methods of Marketing Research, Blackwell, Cambridge, pp. 52-87.

Gefen, D., Rigdon, E.E., Straub, D., 2011. An update and extension to SEM guidelines for administrative and social science research. MIS Q. 35 (2). Available from: https://doi. org/10.1016/j.lrp.2013.01.001 iii-A7.

Gibson, C.F., 2004. IT-enabled Business Change: An Approach to Understanding and Managing Risk. CISR Management Massachusetts Institute of Technology Sep (346), $1-14$.

Gupta, V.K., Huang, R., Niranjan, S., 2010. A longitudinal examination of the relationship between team leadership and performance. J. Leadersh. Organ Stud. 17 (4), 335-350. Available from: https://doi.org/10.1177/1548051809359184.

Hair, J.F., Sarstedt, M., Ringle, C.M., Mena, J.A., 2012. An assessment of the use of partial least squares structural equation modeling in marketing research. J. Acad. Mark. Sci. 40 (3), 414-433. Available from: https://doi.org/10.1007/s11747-011-0261-6. 
Hair, J.F., Jr., Hult, G.T.M., Ringle, C., Sarstedt, M., 2016. A Primer on Partial Least Squares Structural Equation Modeling (PLS-SEM), SAGE Publications, Inc, Washington, D.C.

Hair, J., Hollingsworth, C.L., Randolph, A.B., Chong, A.Y.L., 2017. An updated and expanded assessment of PLS-SEM in information systems research. Ind. Manag. Data Syst. 117 (3), 442-458. Available from: https://doi.org/10.1108/IMDS-04-2016-0130. Henseler, J., Ringle, C.M., Sarstedt, M., 2014. A new criterion for assessing discriminant validity in variance-based structural equation modeling. J. Acad. Mark. Sci. 43 (1), 115-135. Available from: https://doi.org/10.1007/s11747-014-0403-8.

Hsieh, P.J., 2015. Healthcare professionals' use of health clouds: integrating technology acceptance and status quo bias perspectives. Int. J. Med. Inform. 84 (7), 512-523. Available from: https://doi.org/10.1016/j.ijmedinf.2015.03.004.

Huang, T.C.K., Liu, C.C., Chang, D.C., 2012. An empirical investigation of factors influencing the adoption of data mining tools. Int. J. Inf. Manag. 32 (3), 257-270.

doi:10.1016/j.ijinfomgt.2011.11.006.

Kim, H.-W., Kankanhalli, A., 2009. Investigating user resistance to implementation: a status quo bias perspective. MIS Q. 33 (3) 2009, https://doi.org/Article.

Hung, Y.-H., Wang, Y.-S., Chou, S.-C.T., 2007. User Acceptance of E-Government Services. http://aisel.aisnet.org/pacis2007/97. PACIS 2007 Proceedings (Paper 97). Available from: http://aisel.aisnet.org/pacis2007/97.

Kim, H.W., Chan, H.C., Gupta, S., 2007. Value-based adoption of mobile internet: an empirical investigation. Decis. Support Syst. 43 (1), 111-126. Available from: https://doi. org/10.1016/j.dss.2005.05.009.

Kim, D.J., Ferrin, D.L., Rao, H.R., 2008. A trust-based consumer decision-making model in electronic commerce: the role of trust, perceived risk, and their antecedents. Decis. Support Syst. 44 (2), 544-564. Available from: https://doi.org/10.1016/j.dss.2007.07. 001.

Kock, N., 2015. Common method bias in PLS-SEM: a full collinearity assesment approach Int. J. e-Collaboration 11 (4), 1-10. Available from: https://doi.org/10.4018/ijec. 2015100101.

Kock, N., Lynn, G.S., 2012. Lateral collinearity and misleading results in variance-based SEM: an illustration and recommendations. J. Assoc. Inf. Syst. 13 (7), 546-580. Kwon, O., Lee, N., Shin, B., 2014. Data quality management, data usage experience and acquisition intention of big data analytics. Int. J. Inf. Manag. 34 (3), 387-394. Available from: https://doi.org/10.1016/j.ijinfomgt.2014.02.002

Lapointe, L., Rivard, S., 2005. A multilevel model of resistance to information technology implementation. MIS Q. 29 (3), 461-493. Available from: https://doi.org/10.2307/ 25148692.

Lee, J.-H., Song, C., 2013. Effects of trust and perceived risk on user acceptance of a new technology service. Soc. Behav. Personal.: An 41 (3), 587-598. Available from: https:// doi.org/10.2224/sbp.2013.41.4.587.

Lu, H.-P., Hsu, C.-L., Hsu, H.-Y., 2005. An empirical study of the effect of perceived risk upon intention to use online applications. Inf. Manag. Comput. Secur. 13 (2), 106-120. Available from: https://doi.org/10.1108/09685220510589299.

Martins, C., Oliveira, T., Popovič, A., 2014. Understanding the internet banking adoption: a unified theory of acceptance and use of technology and perceived risk application. Int. J. Inf. Manag. 34 (1), 1-13. Available from: https://doi.org/10.1016/j.ijinfomgt.2013.06 002.

McAfee, A., Brynjolfsson, E., 2012. Big Data. The management revolution. Harv. Bus. Rev. 90 (10), 61-68. Available from: https://doi.org/10.1007/s12599-013-0249-5. Nicolaou, A.I., McKnight, D.H., 2006. Perceived information quality in data exchanges: effects on risk, trust, and intention to use. Inf. Syst. Res. 17 (4), 332-351. Available from: https://doi.org/10.1287/isre.1060.0103.

Norzaidi, M.D., Salwani, M.I., Chong, S.C., Rafidah, K., 2008. A study of intranet usage and resistance in Malaysia's port industry. J. Comput. Inf. Syst. 49 (1), 37-47. Available from: https://doi.org/10.1080/08874417.2008.11645304.

Nunnally, J.C., 1978. Psychometric Theory, second ed. MCGraw- Hill College.
Pavlou, P.A., Gefen, D., 2004. Building effective online marketplaces with institution-based trust. Inf. Syst. Res. 15 (1), 37-59. Available from: https://doi.org/10.1287/ isre.1040.0015.

Podsakoff, P.M., MacKenzie, S.B., Lee, J.Y., Podsakoff, N.P., 2003. Common method biases in behavioral research: a critical review of the literature and recommended remedies. J. Appl. Psychol. 88 (5), 879-903. Available from: https://doi.org/10.1037/00219010.88.5.879.

Poon, E.G., Blumenthal, D., Jaggi, T., Honour, M.M., Bates, D.W., Kaushal, R., 2004. Overcoming barriers to adopting and implementing computerized physician order entry systems in U.S. hospitals. Health Aff. 23 (4), 184-190. Available from: https://doi.org/ 10.1377/hlthaff.23.4.184

Rehman, M.H.U., Chang, V., Batool, A., Wah, T.Y., 2016. Big data reduction framework for value creation in sustainable enterprises. Int. J. Inf. Manag. 36 (6), 917-928. Available from: https://doi.org/10.1016/j.ijinfomgt.2016.05.013.

Rigdon, E.E., Sarstedt, M., Ringle, C.M., 2017. On comparing results from CB-SEM and PLS-SEM: five perspectives and five recommendations. Marketing ZFP 39 (3), 4-16. Available from: https://doi.org/10.15358/0344-1369-2017-3-4.

Ringle, C.M., Wende, S., Becker, J.M., 2015. SmartPLS 3.. Available from: http://www. smartpls.com.

Roldán, J L, Sánchez-Franco, M.J., 2012. Variance-Based Structural Equation Modeling: Guidelines for Using Partial Least Squares in Information Systems Research. In: Research Methodologies, Innovations and Philosophies in Software Systems Engineering and Information Systems, IGI Global, Hershey, PA, pp. 193-221. Available from: doi:10.4018/9781-4666-0179-6.ch010.

Sarstedt, M., Hair, J., Ringle, C.M., Thiele, K.O., Gudergan, S.P., 2016. Estimation issues with PLS and CBSEM: where the bias lies!. J. Bus. Res. 69 (10), 3998-4010. Available from: https://doi.org/10.1016/j.jbusres.2016.06.007.

Shmueli, G., Ray, S., Velasquez Estrada, J.M., Chatla, S.B., 2016. The elephant in the room: predictive performance of PLS models. J. Bus. Res. 69 (10), 4552-4564. Available from: https://doi.org/10.1016/j.jbusres.2016.03.049.

Sivarajah, U., Kamal, M.M., Irani, Z., Weerakkody, V., 2016. Critical analysis of Big Data challenges and analytical methods. J. Bus. Res. 70, 263-286. Available from: https://doi. org/10.1016/j.jbusres.2016.08.001.

Straub, D., Boudreau, M., Gefen, D., 2004. Validation guidelines for IS positivist. Commun. Assoc. Inf. Syst. 13, 380-427 https://doi.org/Article.

Venkatesh, V., Bala, H., 2008. Technology acceptance model 3 and a research agenda on interventions. Decis. Sci. J. 39, 273-315.

Venkatesh, V., Davis, F.D., 2000. A theoretical extension of the technology acceptance model: four longitudinal field studies. Manag. Sci. 46 (2), 186-204. Available from: https: //doi.org/10.1287/mnsc.46.2.186.11926.

Venkatesh, V., Morris, M.G., Davis, G.B., Davis, F.D., 2003. User acceptance of information technology: toward a unified view. MIS Q. 27 (3), 425-478. Available from: http:// www.jstor.org/stable/30036540.

Venkatesh, V., Thong, J.Y.L., Xu, X., 2012. Consumer acceptance and use of information technology: extending the unified theory of acceptance and use of technology. MIS Q. 36 (1), 157-178. Available from: https://doi.org/10.1017/CBO9781107415324.004. Verma, S., Bhattacharyya, S.S., Kumar, S., 2018. An extension of the technology acceptance model in the big data analytics system implementation environment. Inf. Process. Manag. 54 (5), 791-806. Available from: https://doi.org/10.1016/j.ipm.2018.01.004. Wu, Y.L., Tao, Y.H., Yang, P.C., 2007. Using UTAUT to explore the behavior of $3 \mathrm{G}$ mobile communication users.. IEEM 2007: 2007 IEEE International Conference on Industrial Engineering and Engineering Management 199-203. doi:https://doi.org/10.1109/ IEEM.2007.4419179.

Yaqoob, I., Hashem, I.A.T., Gani, A., Mokhtar, S., Ahmed, E., Anuar, N.B., Vasilakos, A.V. 2016. Big data: from beginning to future. Int. J. Inf. Manag. 36 (6), 1231-1247. Available from: https://doi.org/10.1016/j.ijinfomgt.2016.07.009.

$\mathrm{Yu}, \mathrm{C} .-\mathrm{S} ., 2$ 2012. Factors affecting individuals to adopt mobile banking: empirical evidence from the UTAUT model. J. Electron. Commer. Res. 13, 104-121.

Zikmund, W.G., Scott, J.E., 1974. A Multivariate Analysis of Perceived Risk Self-Confidence and Information Sources, ACR North American Advances. 